\title{
O sistema estadual de participação popular e cidadã e o gabinete digital do governo Tarso Genro no Rio Grande do Sul
}

\author{
Vinicios Gonchoroski de Oliveira \\ Angela Cristina Trevisan Felippi
}

\begin{abstract}
Resumo
O artigo discute as Tecnologias de Informação e Comunicação (TIC) na gestão pública, em específico, no caso do governo do Rio Grande do Sul, durante a administração Tarso Genro (2011-2014). O objetivo é compreender o processo de adoção das TIC como forma de promover a participação cidadã, analisando um mecanismo do Sistema Estadual de Participação Popular e Cidadã (SISPARCI), o Gabinete Digital (GD). A progressiva presença das TIC na gestão pública é analisada desde a formação do meio técnico-científico-informacional enquanto elemento explicativo dos fenômenos contemporâneos. Em termos metodológicos, adota-se a ótica dos atores governamentais e da sociedade civil. A pesquisa se situa numa perspectiva crítico-cultural da tecnologia. Os resultados evidenciam a existência de dificuldades na implantação do sistema, a ocorrência de alterações na prática cidadã durante a vigência do SISPARCI e a descontinuidade da proposta com o encerramento do governo Tarso Genro.
\end{abstract}

Palavras-chave | Gestão pública; participação; Rio Grande do Sul; Tarso Genro; tecnologia da informação e comunicação.

Classificação JEL | H70 O32 Z18

The state system of popular and citizen participation and the digital cabinet of the Tarso Genro government in Rio Grande do Sul

\begin{abstract}
The article discusses the presence of Information and Communication Technologies (ICT) in public management, specifically in the case of the Rio Grande do Sul State government during the administration of Tarso Genro (2011-2014). The purpose is to understand the process of ICT adoption as a way of intensifying citizen participation, analyzing a mechanism of the State System of Popular and Citizen Participation (SISPARCI), the Digital Office (GD). The gradual presence of ICT in public administration is analyzed from the perspective of the technicalscientific-informational environment as a key element in explaining contemporary phenomena.
\end{abstract}


Methodologically, it is adopted the perspective of government actors and civil society. The research is situated in a critical-cultural perspective of technology. The results point out difficulties in the implementation of the system, the occurrence of changes in the citizenship practice during the SISPARCI term and the discontinuity of the proposal with the closure of the Tarso Genro government.

Keywords | Information and communication technology; participation; public management; Rio Grande do Sul; Tarso Genro.

JEL Classification | H70 O32 Z18

\section{El sistema estatal de participación popular y ciudadana y el gabinete digital del gobierno de Tarso Genro en el Rio Grande do Sul}

\section{Resumen}

El artículo discute las Tecnologías de la Información y la Comunicación (TIC) en la gestión pública, específicamente, en el caso del gobierno de Río Grande do Sul, durante la administración de Tarso Genro (2011-2014). El objetivo es comprender el proceso de adopción de las TIC como forma de promover la participación ciudadana, analizando un mecanismo del Sistema Estatal de Participación Popular y Ciudadana (SISPARCI), el Gabinete Digital (GD). La progresiva presencia de las TIC en la gestión pública se analiza desde la formación del entorno técnico-científico-informacional como elemento explicativo de los fenómenos contemporáneos. En términos metodológicos, se adopta la perspectiva de los actores gubernamentales y de la sociedad civil. La investigación se sitúa en una perspectiva críticocultural de la tecnología. Los resultados muestran la existencia de dificultades en la implementación del sistema, la ocurrencia de cambios en la práctica de la ciudadanía durante la vigencia del SISPARCI y la discontinuidad de la propuesta con el fin del gobierno de Tarso Genro.

Palabras clave | Gestión pública; participación; Rio Grande do Sul; Tarso Genro; tecnología de la información y comunicación.

Clasificación JEL | H70 O32 Z18

\section{Introdução}

A emergência das Tecnologias da Informação e Comunicação (TIC) ocorrida desde o final do século passado tem gerado expectativa sobre seu potencial em diversos campos, dentre os quais a gestão pública, especialmente na perspectiva da gestão democrática. A posição é encontrada em boa parte da literatura da área, assim como em documentos de governos e de organismos internacionais, como a Organização das Nações Unidas (ONU). Os relatórios da última década da ONU evidenciam as TIC como instrumentos capazes de qualificar os processos de participação cidadã 
no ambiente governamental (ONU, 2016). Por outro lado, há uma corrente de pesquisa crítica que aponta para as fragilidades do uso das tecnologias para o avanço da participação democrática ao introduzir neste debate o caráter social da tecnologia, vinculando-a diretamente a processos sociais e culturais.

Nesse sentido, este artigo propõe, a partir de uma análise da perspectiva crítica sobre os usos das TIC pelo Estado, identificar como se deu o processo de adoção das tecnologias para a construção de uma democracia digital amparada na ampliação dos espaços de participação civil e deliberação durante a gestão pública do governador Tarso Genro (Partido dos Trabalhadores (PT) ${ }^{1}$, no período de 2011 a 2014, no Rio Grande do Sul, Brasil.

Toma-se como caso a criação e implantação do Sistema Estadual de Participação Popular e Cidadã (SISPARCI), que foi um complexo conjunto de instrumentos de gestão voltado à participação e transparência das decisões públicas elaborado na referida gestão do governador Tarso Genro, e, como parte dele, a experiência do Gabinete Digital (GD). Esse se caracterizou como um portal que intermediava a participação da população gaúcha com o governo do Estado. O SISPARCI e seus instrumentos foram destaque mundial pela inovação em práticas de democracia digital, apesar do curto tempo de permanência ${ }^{2}$ dessas experiências no âmbito da gestão pública.

Assim, tem-se na gestão de Tarso Genro uma tentativa do aprofundamento de experiências participativas por meio das ferramentas tecnológicas, a partir da compreensão do seu potencial democratizante. Isto se evidencia já no seu programa de governo e projeto de gestão, que entendia a adoção das ferramentas da democracia digital nos processos participativos como potências para o desenvolvimento do território gaúcho, alicerçado numa concepção de desenvolvimento contemporâneo que privilegia a tomada coletiva das decisões, a ampliação da cidadania e uma forte crença nas oportunidades que o desenvolvimento tecnológico proporciona.

\footnotetext{
${ }^{1}$ A coligação que elegeu Tarso Genro, a Unidade Popular, era formada pelo Partido dos Trabalhadores (PT), Partido Socialista Brasileiro (PSB), Partido Comunista do Brasil (PCdoB) e Partido da República (PR). Convém observar que nas eleições a governador do Rio Grande do Sul, em 2010, Tarso Genro recebeu 54\% dos votos válidos, sendo eleito ainda no primeiro turno.

${ }^{2}$ O SISPARCI auferiu ao menos sete prêmios apurados por esta pesquisa, entre os quais se destacam o Prêmio Bank Beneficiary Feedback Awards, concedido pelo Instituto do Banco Mundial, em 2012, à iniciativa do Gabinete Digital, e o Prêmio da Organização das Nações Unidas (ONU) para o SISPARCI, em 2013.
} 


\section{Procedimentos metodológicos}

O artigo integra uma pesquisa desenvolvida no âmbito do Programa de PósGraduação em Desenvolvimento Regional da Universidade de Santa Cruz do Sul, entre os anos de 2016-2019, relacionada à linha de pesquisa Estado, Instituições e Democracia. Filia-se a um conjunto de estudos da área de Desenvolvimento Regional que busca compreender os processos político-participativos e sua relação com o aprofundamento da democracia e, no caso, preocupa-se com a inserção recente das TIC nestes processos, tanto nos seus limites e avanços.

No que diz respeito aos procedimentos metodológicos, o estudo vale-se da (1) pesquisa bibliográfica e (2) pesquisa documental e (3) de entrevistas semiestruturadas. Foram fundamentais sobre democracia participativa e deliberativa, gestão pública, transparência, participação e TIC, ancoradas numa perspectiva crítica das tecnologias.

A pesquisa documental se debruçou sobre um conjunto de materiais que incluem o Programa de Governo de Tarso Genro, do relatório do Balanço 2011-2014 do GD, de leis, decretos e notícias publicadas na imprensa. Os documentos permitiram dados para a compreensão das intenções e do processo de democracia digital instituído no governo estudado, bem como elementos para cotejar as falas dos atores entrevistados.

$\mathrm{Na}$ pesquisa documental, merecem destaque os relatórios ${ }^{3}$ produzidos pela Fundação Getúlio Vargas (FGV) ao governo do Estado, a partir de uma consultoria de assessoramento de implementação do GD, durante os anos iniciais deste, cujo objetivo foi auxiliar na construção do desenho e orientação das primeiras ferramentas do $\mathrm{GD}^{4}$. O destaque fica por conta desses relatórios serem documentos inéditos e apresentarem informações sobre a dinâmica de funcionamento das primeiras ferramentas do GD, bem como as bases conceituais e os resultados alcançados com elas durante o primeiro ano da experiência. E no caso do Portal do GD, por ser o registro da memória da experiência, ele foi analisado a partir de materiais off-line obtidos junto a Companhia de Processamento de Dados do Rio Grande do Sul (Procergs), via Lei de Acesso à Informação (Lei N. 12.527/2011). Uma vez que o portal foi descontinuado, os registros dessa experiência foram excluídos da internet.

As entrevistas semiestruturadas foram centrais na pesquisa. Foram 15 entrevistas com 14 sujeitos. Eles se dividem em: integrantes do primeiro e segundo escalões do

\footnotetext{
${ }^{3}$ Relatório com Plano Conceitual de Diretrizes Estratégicas do Gabinete Digital, de 2011, Relatório da Sistemática do Diálogo “O Governador Responde”, de 2011, Relatório da Sistemática do Diálogo "O Governador Pergunta”, de 2012, $1^{\circ}$ Relatório de Monitoramento da Implementação e Avaliação do Gabinete Digital, de 2011 e $2^{\circ}$ Relatório de Monitoramento da Implementação e Avaliação do Gabinete Digital, de 2012.

${ }^{4}$ Governador Pergunta, Governador Responde e Governo Escuta.
} 
governo estadual do Rio Grande do Sul (RS) que estiveram à frente da gestão no período de 2011 a 2014, bem como representantes de organizações da sociedade civil, essas constituídas em gestões estaduais anteriores para conduzir processos de participação da sociedade gaúcha, entre os quais se destaca o Comitê de Consulta Popular, os Conselhos Regionais de Desenvolvimento e pesquisadores ligados a universidades. O conjunto de entrevistados foi sendo definido e identificado durante a realização da pesquisa, seguindo a técnica da bola de neve (VINUTO, 2014). Os dois grupos de entrevistados (Quadro 1) foram acionados para, com o primeiro grupo, levantar informações e avaliações sobre o SISPARCI, e, com o segundo, compreender a percepção da sociedade civil organizada, enquanto usuária e articuladora do sistema, fazendo cotejamento das percepções dos dois grupos. 


\section{Quadro 1 - Entrevistados para a pesquisa}

\begin{tabular}{|c|c|c|c|}
\hline Cargo/Função ${ }^{5}$ & Tema & Meio & Data \\
\hline $\begin{array}{l}\text { Pesquisador da Universidade de Santa Cruz } \\
\text { do Sul }\end{array}$ & Consulta Popular ${ }^{6}$ & Pessoalmente & $01 / 12 / 2017$ \\
\hline $\begin{array}{l}\text { Coordenador da Divisão Digital do Dep. de } \\
\text { Participação Cidadã - Deparci da SPGPC }\end{array}$ & $\begin{array}{r}\text { SISP } \\
\text { Gabine }\end{array}$ & Telefone & $11 / 12 / 2017$ \\
\hline $\begin{array}{l}\text { Presidente do Corede-Norc (2012-2016) e } \\
\text { Integrante da Comissão Estadual da Consulta } \\
\text { Popular } \\
\text { Vice-presidente do Corede-Norc (2008-2012) }\end{array}$ & Consulta Popular & Pessoalmente & $27 / 12 / 2017$ \\
\hline \multirow{2}{*}{$\begin{array}{l}\text { Diretor do Departamento de Participação } \\
\text { Cidadã - Deparci da SPGPC }\end{array}$} & $\begin{array}{c}\text { SISPARCI e } \\
\text { Gabinete Digital }\end{array}$ & \multirow[t]{2}{*}{ Telefone } & $06 / 01 / 2018$ \\
\hline & Consulta Popular & & $12 / 01 / 2018$ \\
\hline $\begin{array}{l}\text { Coordenador Geral do Gabinete Digital } \\
\text { (CGD) (2011-2014) } \\
\text { Secretário da Secretaria-Geral do Governo } \\
\text { (SGG) (2013-2014) e } \\
\text { Chefe de Gabinete do Governo do Estado } \\
\text { do RS (2011-2013) }\end{array}$ & $\begin{array}{l}\text { SISPARCI e } \\
\text { Gabinete Digital }\end{array}$ & Pessoalmente & $26 / 01 / 2018$ \\
\hline $\begin{array}{l}\text { Coordenador Executivo do Gabinete Digital } \\
(2012-2014)\end{array}$ & $\begin{array}{c}\text { SISPARCI e } \\
\text { Gabinete Digital }\end{array}$ & Skype & $29 / 01 / 2018$ \\
\hline Articulador de Políticas Digitais do GD & $\begin{array}{c}\text { SISPARCI e } \\
\text { Gabinete Digital }\end{array}$ & Telefone & $13 / 032018$ \\
\hline $\begin{array}{l}\text { Presidente } \\
\text { Comissão }\end{array}$ & $\begin{array}{l}\text { SISPARCI e Consulta } \\
\text { Popular }\end{array}$ & Telefone & $13 / 03 / 2018$ \\
\hline $\begin{array}{l}\text { Coordenador da Divisão Digital do Dep. de } \\
\text { Participação Cidadã (Deparci) da SPGPC }\end{array}$ & Consulta Popular & Pessoalmente & $12 / 05 / 2018$ \\
\hline Secretário da SPGPC & $\begin{array}{c}\text { SISPARCI e } \\
\text { Gabinete Digital }\end{array}$ & Pessoalmente & 2018 \\
\hline $\begin{array}{l}\text { Assessora de Planejamento da Companhia de } \\
\text { Processamento de dados do RS - Procergs }\end{array}$ & Consulta Popular & Telefone & $07 / 06 / 2018$ \\
\hline Governador do RS (2011-2014) & $\begin{array}{c}\text { Democracia, } \\
\text { Participação, Sisparci }\end{array}$ & Pessoalmente & $11 / 07 / 2018$ \\
\hline Presidente do Fórum dos Coredes & Consulta Popular & Pessoalmente & $22 / 08 / 2018$ \\
\hline Pesquisador (aposentado) da UFRGS & Consulta Popular & Pessoalmente & $22 / 08 / 2018$ \\
\hline
\end{tabular}

Fonte: Elaborado pelxs autorxs a partir de Oliveira (2019).

\footnotetext{
${ }^{5}$ Embora não tenha sido solicitado sigilo quanto ao nome dos entrevistados, optou-se por nomeá-los por seus cargos quando do período estudado por se entender que, para a pesquisa, o teor das entrevistas está relacionado ao seu lugar de fala institucional, portanto, o cargo ou a função que ocupavam.

${ }^{6}$ Consulta Popular (CP) é um mecanismo instituído pelo Governo do Estado do Rio Grande do Sul em 1998, por meio da Lei 11.179, pelo qual a população gaúcha define prioridades orçamentárias. Atualmente está atrelado ao processo de definição dos projetos de desenvolvimento das regiões do Estado, conduzido pelo Conselho Regional de Desenvolvimento (Coredes).

${ }^{7}$ A Secretaria de Planejamento, Gestão e Participação Cidadã (SPGPC) é uma das secretarias que integra a Estrutura da Governadoria do Estado e tinha por objetivo as funções de planejamento, gestão, coordenação e avaliação das políticas e ações do próprio governo do estado (vide Lei N. 13.601 de janeiro de 2011 e Decreto N. 49.624, de setembro de 2012).
} 


\section{A presença das tecnologias na sociedade}

A perspectiva teórica da potencialidade do uso das TIC se associa à compreensão da racionalidade e da tecnicidade instrumental enquanto paradigma funcionalista de transformação do homem, da natureza e do espaço (sociedade em movimento).

O atual estágio de desenvolvimento da sociedade, proporcionado pelos avanços no campo da ciência e da técnica, possibilitou às sociedades modernas experenciarem um modelo de desenvolvimento antes inimaginável. Tais avanços correspondem à firmação do meio técnico-científico-informacional (SANTOS, 2014) enquanto elemento-chave de explicação e compreensão dos fenômenos contemporâneos. Como nunca na história, utilizam-se os recursos tecnológicos para expandir as potencialidades humanas perante o meio (ações antrópicas), modificando e ressignificando a práxis dialógica (processos de comunicação), e utiliza-a para garantir a sua liberdade. Ou, como aponta o filósofo brasileiro Álvaro Vieira Pinto (2005), a disseminação do uso da máquina e do computador guarda intrínseca relação com o argumento que para o ser humano superar as desigualdades seria necessário entrar na era tecnológica.

Os avanços tecnológicos resultam de um processo racional, de acúmulo de conhecimento, e são desenvolvidos para suprir as necessidades humanas, sejam elas vinculadas à esfera social (ampliação dos canais de comunicação e intercâmbio de conhecimento), ao Estado (modernização dos governos e da administração pública), ao mercado (processo de desenvolvimento das forças produtivas da sociedade) ou à nova Divisão Internacional do Trabalho (DIT).

Isto significa dizer que a concepção de meio técnico-científico-informacional constitui num importante conceito formulado por Milton Santos para demonstrar a ampliação da ciência e da técnica e dos processos de produção e reprodução do meio como indutores para o alcance do desenvolvimento. A ciência, a tecnologia e a informação formam a nova base técnica da vida e são o centro das relações. Pari passu seu emprego no tecido social sendo os mais diversos, torna-se plausível, ou mesmo compreensível, que o homem moderno deposite expectativas favoráveis em relação aos benefícios proporcionados pela ‘instrumentalização’ e ‘tecnificação’ do espaço e da natureza.

O desenvolvimento da computação, das telecomunicações, da radiodifusão e da internet, no decorrer da segunda metade do século XX, direcionou o mundo a um novo modelo de sociedade. Se no período pré-industrial o elemento transformador da sociedade era proveniente da energia natural e no período industrial a energia passa a ser produzida e transformada com a mecanização deste processo, já no período pós-industrial a informação, que se vale do conhecimento e da tecnologia, são os fatores estratégicos para o desenvolvimento. 
As estupendas criações cibernéticas com que hoje nos maravilhamos resultam apenas do aproveitamento da acumulação social do conhecimento, que permitiu fossem concebidas e realizadas. Não derivam das máquinas anteriores enquanto tais, mas do emprego que o homem fez delas [...] (PINTO, 2005, p. 20).

Como descreve Thompson (2002, p. 24), o indivíduo utiliza dos recursos dos meios de informação e comunicação, que incluem "meios técnicos de fixação e transmissão, as habilidades, competências e formas de conhecimento empregadas na produção, transmissão e recepção da informação e do conteúdo simbólico", como instrumentos de ação para intervir no curso dos acontecimentos de sua história. Pois as "ações simbólicas podem provocar reações, liderar respostas de determinado teor, sugerir caminhos e decisões, induzir a crer e a descrer, apoiar os negócios do Estado ou sublevar as massas em revolta coletiva (THOMPSON, 2002, p. 24).

Para Pinto (2005, p. 362),

a tecnologia e os maquinismos de qualquer espécie que a materializam assumem duplo e profundo significado: o de ser ao mesmo tempo manifestação da razão humana no grau de desenvolvimento que alcançaram em cada momento e em certa comunidade nacional, sob forma de consciência para si; e o de fornecer o condicionamento objetivo, a força, o "motor" do processo de evolução da mesma razão.

Compartilha-se da afirmação de Castells (2005, p. 43) quanto o seu entendimento de que o paradigma do determinismo tecnológico se revela algo parcialmente infundado. A tecnologia não é capaz de determinar a sociedade, não é autônoma e independente da sociedade. Pelo contrário, ela corresponde à própria sociedade, e esta, por sua vez, "não pode ser entendida ou representada sem suas ferramentas tecnológicas".

A relação dialética entre sociedade e tecnologia se mostra paradoxal à medida que os elementos descritos por Castells (2005), que dependem de ampla e complexa interatividade para resultarem na transformação tecnológica, são parte intrínseca da sociedade. Em tese, não poderiam, assim como a tecnologia, ser percebidos como fatores à parte da sociedade. Como quando o autor destaca que "novas formas e processos sociais não surgem em consequência de transformação tecnológica" (CASTELLS, 2005, p. 43). Mas, uma vez instituído no tecido social, o homem passa a fazer uso, e o uso que ele faz cria "novas formas e canais de comunicação, moldando a vida e, ao mesmo tempo, sendo moldadas por ela" (CASTELLS, 2005, p. 40). 
Para Thompson (2002, p. 24), as TIC são recursos tecnológicos que o homem utiliza para "intervir no curso dos acontecimentos, influenciar as ações dos outros e produzir eventos por meio da produção e transmissão de formas simbólicas". Seu uso seria capaz de alterar de forma significativa as relações sociais à medida que novas relações de poder são estabelecidas no tecido social, a partir de seu uso e de seu potencial.

Castells (2005) explica que a integração das esferas da vida social por meio da ideia central da interconexão (em rede) mudou radicalmente a forma com que as sociedades contemporâneas interagem e se comunicam entre si, acessam e buscam informações. Mormente, quanto a potencialidade do uso das TIC enquanto instrumento democratizador e fundamental para $\mathrm{O}$ fortalecimento $\mathrm{e}$ aperfeiçoamento da práxis democrática e dos mecanismos participativos que dela resultam e caracterizam os Estados-nações democráticos. Contudo,

nunca foi tão profundo o sentimento de desconexão e de exclusão em relação às transformações que marcam o espaço e o tempo do mundo. $[. .$.$] nunca tantos grupos estiveram tão ligados ao resto do mundo por via$ do isolamento, nunca tantos foram integrados por via do modo como são excluídos. (SANTOS, 2002, p. 17).

O sofismo em torno das promessas e facilidades com o desenvolvimento da tecnologia, é percebido nas mais diversas áreas da vida humana, assim como as alterações nas múltiplas escalas, sejam espaciais ou temporais, da ação social.

Em meio à onipresença das TIC em praticamente todas as esferas da vida humana, não se pode desconsiderar a reflexão crítica do quanto as sociedades modernas se tornaram dependentes dos recursos tecnológicos e das potencialidades e promessas que delas resultam, sobremaneira na modernização dos processos produtivos, do Estado, da pólis, da esfera pública e política, da democracia e dos seus processos correlatos à participação, deliberação, empoderamento e comunicação.

\section{A participação cidadã no governo Tarso Genro: TIC e o SISPARCI}

O Rio Grande do Sul, lócus do estudo, é um Estado da federação brasileira com uma história recente (30 anos) de inovações no âmbito da democracia participativa, com destaque para as experiências do Orçamento Participativo (OP), da Consulta Popular (CP), dos Conselhos Regionais de Desenvolvimento (Coredes) e dos Conselhos Municipais de Desenvolvimento (Comudes), processos estes iniciados após a abertura democrática dos anos 1980 e que, em parte, tiveram continuidade nos diferentes governos do estado eleitos por sufrágio universal, conferindo certo protagonismo desse Estado em experiências de democracia participativa no país. 
Nesse contexto, o governo Tarso Genro, eleito no pleito de 2010 pelo Partido dos Trabalhadores, tinha como ênfase a promoção de uma gestão participativa, com controle público, transparente, de modo a constituir uma esfera democrática em que houvesse partilha do poder e articulação política, especialmente combinando as democracias representativa e participativa. A ideia de combinar estes dois modelos de democracias vai ao encontro da trajetória política do governador, assim como a do Partido dos Trabalhadores, muito embora, neste caso, havia um caráter inovador ao combinar elementos da democracia representativa e participativa, que foi a inclusão das TIC nesse processo e as expectativas em torno delas.

Isto se evidencia já no seu Programa de Governo, ao entender que as tecnologias seriam um fator-chave para promover o desenvolvimento econômico, o combate à corrupção, ao patrimonialismo e às desigualdades (PROGRAMA DE GOVERNO TARSO, 2010).

O protagonismo da sociedade na esfera pública tinha por finalidade a construção de uma nova perspectiva de transformação social à luz dos pressupostos da democracia participativa e deliberativa. Vislumbrava-se uma gestão participativa dialógica, transversal e sistêmica que integrasse os diversos sujeitos e atores da sociedade, de modo a se construir uma outra relação entre Estado e sociedade. "Todos os segmentos da sociedade dialogando e construindo juntos. É assim que o Rio Grande do Sul vai crescer no ritmo do Brasil" (PROGRAMA DE GOVERNO TARSO, 2010, p. 8).

Como forma de atender aos objetivos do plano de governo, de possibilitar a participação direta e cidadã, viabilizando a publicização da informação, o debate, a votação de propostas e demandas, a fiscalização e o acompanhamento das ações do estado, o governo do RS desenvolveu o SISPARCI. A experiência do SISPARCI ganha destaque na gestão de Tarso Genro por representar uma proposta de formulação, normatização e articulação dos processos participativos com as estruturas de governo, o qual era formado por um conjunto de instrumentos de participação que atuavam de forma sistêmica na elaboração, monitoramento e avaliação das políticas públicas de desenvolvimento (RIO GRANDE DO SUL, 2012, online, grifos nossos). Ao todo, o sistema incluía quatro dimensões: as decisões orçamentárias, controle social, diálogos sociais e a participação digital. Integravam o SISPARCI, entre outros (Figura 1), o Gabinete Digital e a Consulta Popular, experiências estas que, direta ou indiretamente, faziam uso das TIC visando a participação cidadã e o aprofundamento da democracia. 


\section{Figura 1 - Organograma do SISPARCI}

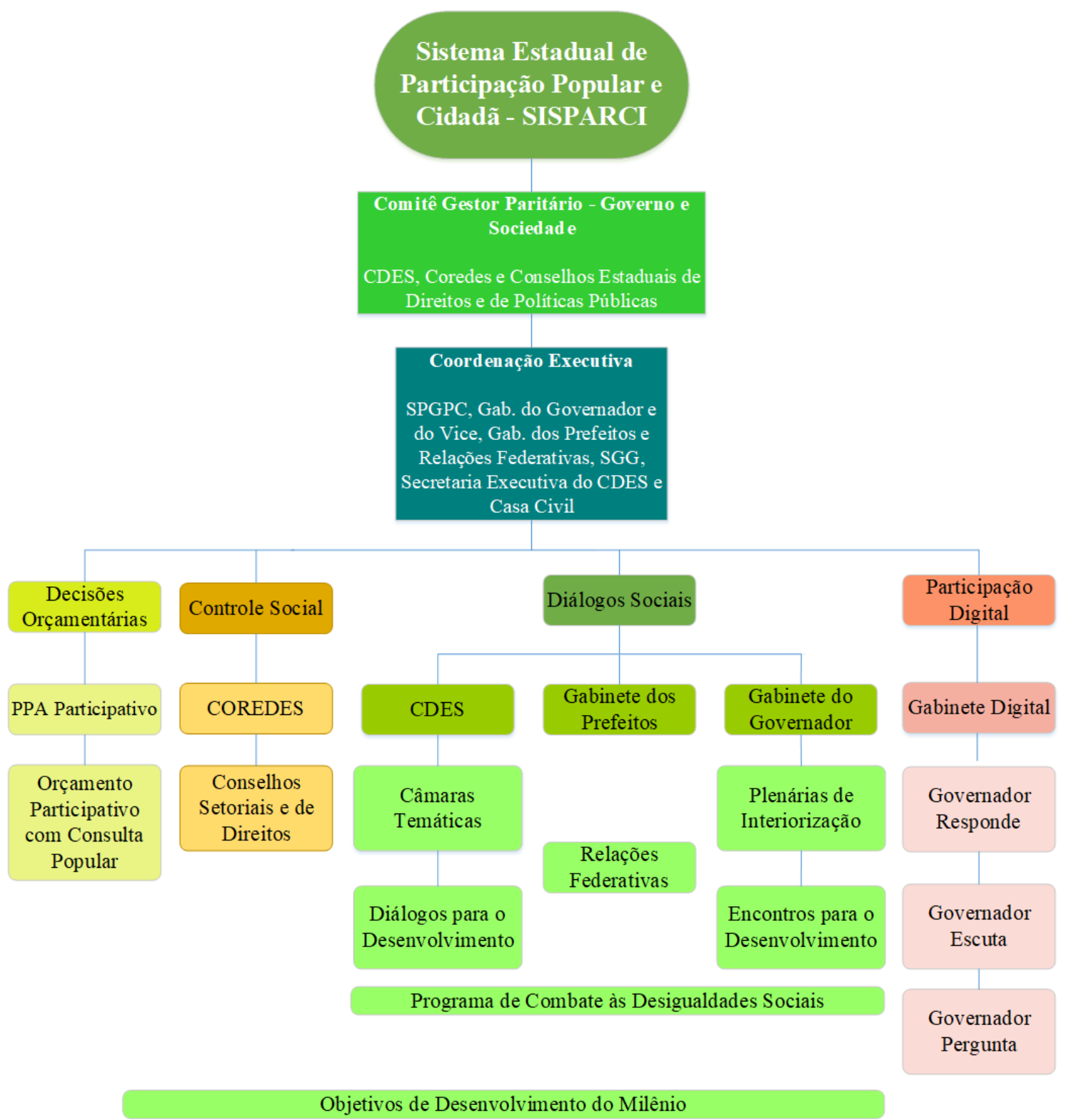

Fonte: Oliveira (2019, p. 192).

O desenvolvimento do SISPARCI refletia o interesse do governo de romper o desafio de promover a democratização do Estado por meio do desenvolvimento de mecanismos institucionais capazes possibilitar a ampla participação da sociedade, a promoção da justiça e da inclusão social, o fomento ao crescimento econômico e o desenvolvimento sustentável.

O principal desafio [...] é formular e debater no Estado, com toda a sociedade, um programa gaúcho capaz de apresentar soluções consistentes aos problemas estaduais e atender às necessidades essenciais do nosso povo. É preciso construir um programa que seja tão 
transformador como o que está sendo realizado no Brasil (PROGRAMA DE GOVERNO TARSO, 2010, p. 2).

No intuito de organizar um sistema de participação popular para a definição de investimentos estratégicos, regionais e microrregionais, que combinasse a participação presencial direta dos cidadãos a nível local e regional, com a participação digital por meio do uso das novas tecnologias, foram realizados quatro seminários ao longo dos primeiros anos do governo, que discutiram a formulação teórica e metodológica do Sistema de Participação Cidadã. Os encontros reuniram diversos analistas e pesquisadores nacionais e internacionais com vistas ao alinhamento da proposta, o tocante aos seus objetivos, desenhos de fluxos e o papel dos órgãos evolvidos.

Em 30 de outubro de 2012, por meio do Decreto N. 49.765, instituiu-se o Sistema Estadual de Participação Popular e Cidadã (SISPARCI), que era formado por um conjunto de instrumentos de participação que atuariam de forma sistêmica na elaboração, monitoramento e avaliação das políticas públicas. $O$ texto do decreto reforçou alguns pressupostos presentes no início de campanha ao governo, como o compromisso de ampliar a participação popular e cidadã, o diálogo da esfera pública com todos os segmentos da sociedade, a necessidade de reconhecer e combinar diversas formas de interlocução presencial e digital, e a importância de se desenvolver políticas de proteção, inclusão social, de combate à miséria e valorização dos valores republicanos.

Mesmo após a realização dos quatro seminários que serviram para aprimorar e consolidar o SISPARCI junto à esfera governamental e à sociedade, a ideia de se ter desenvolvido um sistema de participação com integração sistêmica ainda era questionável. Vale observar, que o próprio desenho do SISPARCI remetia a uma estrutura de participação hierárquica. As dimensões e suas instâncias não possibilitavam o entendimento de que o sistema propiciava uma integração efetiva entre si, do ponto de vista sistêmico e de uma processualidade horizontal. Vale dizer, que esta é uma das principais críticas feitas deste sistema.

Em entrevista, a fala da Presidente do Corede-Sul e Integrante da Comissão Estadual da CP, que fez parte de um grupo da Secretaria de Planejamento responsável por analisar e avaliar os diferentes nós do sistema e a sua proposta em 2013 (GT SISPARCI), reforçou esse entendimento. Segundo a entrevistada, a ideia defendida dentro do governo de que o SISPARCI representava de fato um sistema de participação, com integração e articulação sistêmica entre as dimensões e instâncias, não era identificado na prática. Embora houvesse a existência de diferentes canais de participação e de interação entre governo e sociedade, havia a necessidade de se construir mais diálogos horizontais. Na prática, o que havia é que, "quase sempre", cada um dos canais de participação realizava um "um diálogo com o governo do Estado, mas não entre eles. Então, para mim, mesmo com as 
tecnologias favoráveis, nós tivemos dificuldades para estabelecer diálogos entre os diferentes espaços" (PRESIDENTE DO COREDE-SUL E INTEGRANTE DA COMISSÃO ESTADUAL DA CP, 2018).

Neste sentido, a entrevistada argumenta, por exemplo, que o CDES não dialogava com os Coredes.

Tinham pautas diferentes, não tinham nenhuma convergência. Embora tivesse um representante lá dentro, mas era mais um. Mas o CDES vinha nas regiões sem um diálogo com os Coredes, ou o Corede da região com antecedência. Ele participava, mas aí já como um ator como tantos outros. Então, assim, bom, mas se é um elo, vamos discutir um pouco mais isso. Então, para mim, o sistema ele tem que dentro desses diferentes espaços ter interlocuções.

Em sentido contrário, a percepção do Secretário da Secretaria-Geral de Governo (SGG) e Coordenador Geral do Gabinete Digital (2018) é de que o sistema propiciava o diálogo e uma integração entre as suas dimensões e instâncias. Ou seja, o sistema possuía uma visão sistêmica. O exemplo disso foi o movimento do Passe Livre, em 2013.

\footnotetext{
${ }^{8}$ Durante as manifestações de junho de 2013, também conhecidas como Jornadas de Junho, ocorreram diversas mobilizações sociais organizadas pela internet em defesa de diversas demandas e reivindicações da sociedade, como saúde, educação, contra os gastos com a Copa do Mundo de 2014, passe livre no transporte público, entre outras. Por meio da sua ferramenta do Governo Escuta (GE) do Gabinete Digital, realizou-se uma audiência pública em que o governador recebeu lideranças do movimento e manifestantes para dialogar. Esta audiência foi ainda transmitida pela internet. Assim, o Passe Livre Estudantil foi anunciado pelo governador em 27 de junho de 2013 (BALANÇO 2011-2014 do GD, p. 25)
} 
feito pelo restante do Sistema, que era mobilizar as pessoas para votar e participar (SECRETÁRIO DA SGG E COORDENADOR GERAL DO GD, 2018).

Porém, pode-se dizer que, embora se possa questionar o desenho do SISPARCI quando ao fato de haver ou não integração e articulação sistêmica entre as suas dimensões e instâncias à luz das distintas percepções dos entrevistados, reconhecese que, para além da visão sistêmica, é necessário que as dimensões e instâncias também tenham capacidades de articulações e sejam prepositivas. Isto porque, como se observou nas entrevistas, houve certa falta de apoio e o não entendimento, inclusive, de membros da própria gestão do governo e da Assembleia Legislativa em relação ao que se de fato se almejava com o sistema.

$\mathrm{Na}$ fala do Secretário Geral de Governo (SGG) e Coordenador Geral do Gabinete Digital (2018), para além da necessidade de o governo abraçar a agenda da participação, era preciso possuir metodologias apropriadas, capacidade de coordenação interna, "vencer as amarras institucionais, [...] até resistências, por exemplo, do Legislativo, [...] que muitas vezes percebe a participação da cidadania como um esvaziamento das suas funções". Pois, à medida que se avança na pauta da participação e deliberação das decisões ao demos e, portanto, considerando-se um maior empoderamento deste, pode-se ter um esvaziamento das funções do poder executivo e legislativo.

Como identifica Gomes (2005), ao tratar sobre os graus de democracia digital, à medida que se tem um modelo de democracia mais direta, isto é, onde as tomadas de decisões são diretas sem a interveniência de uma esfera política do tipo representativa, o Estado, ainda que numa visão utópica, passaria a ser governado por plebiscitos on-line, restando à esfera política, as funções meramente administrativas, já que o cidadão substituiria os representantes políticos na produção da decisão.

No caso do governo petista, o fator cultural da sociedade e a cultura interna do poder executivo foram limitadores para a implementação do SISPARCI. Isto porque

a cultura da sociedade e a cultura interna, também, das instituições. [...] o servidor público, as estruturas de comando interno, elas são muito reativas, são pouco abertas, tem uma lógica, também, às vezes uma racionalidade, tem leis também que colocam para o gestor dificuldades para que ele ouça a sociedade (SECRETÁRIO DA SGG E COORDENADOR GERAL DO GD, 2018).

O Secretário da SPGPC (2018) enfatiza a dificuldade existente de convencer os próprios membros do governo a adotarem um modelo de gestão mais participativo 
e inclusivo, cujas decisões fossem tomadas à luz dos pressupostos da democracia participativa/deliberativa, ao invés de reproduzir um modelo de governo em que as tomadas de decisões são centralizadas. Isto é, "governar com um gabinete fechado, tomando decisões apenas nos chamados gabinetes, cada vez mais internos" (SECRETÁRIO DA SPGPC, 2018).

O governante que não se abrir, não comprometer, com esse processo, ele acaba reproduzindo essa ideia limitada da democracia tradicional. E eu acho que isso, infelizmente, nos nossos governos, também ocorre em grande parte. Claro que aí tem uma visão de exercício de poder que depende muito da cabeça de cada indivíduo. A gente brinca, fazia uma brincadeira, ou faz uma brincadeira, com os secretários, né, quem é que vai abrir mão da caneta para tomar a decisão? Mas se trata disso (SECRETÁRIO DA SPGPC, 2018, grifos nossos).

Como o SISPARCI se tratou de uma política de governo e não de Estado, já que foi instituído por decreto e não por lei, faz-se importante mencionar que o sistema teve existência por um período de dois anos. Ou seja, foi concebido na gestão do governo Tarso e, com a sua não reeleição nas eleições de 2014, foi descontinuado na gestão seguinte. O tempo de vigência não permitiu seu amadurecimento, entendimento e avanços, isto tanto nas bases do governo como na sociedade.

Se por um lado a implementação por lei exige um tempo maior de tramitação e tem mais força normativa, o decreto tem um tempo menor de tramitação e uma menor força normativa, sendo mais fácil sua alteração e, até mesmo, descontinuidade. Talvez este seja um ponto a se observar quando se trata da implementação de políticas que visem aumentar a participação da sociedade civil nas arenas decisórias via TIC.

\section{A práxis das TIC: o Gabinete Digital}

O GD surge da ideia de se desenvolver um canal específico de participação e de diálogo entre a sociedade civil e o governo do Estado do RS, enquanto componente de um sistema mais amplo, o qual pudesse servir como uma espécie de laboratório de experimentação democrática a partir do uso das ferramentas digitais.

A intenção de desenvolver um novo e inovador canal interativo entre governo e sociedade teve origem ainda na fase da campanha eleitoral de Tarso Genro, em 2010. Seu programa de governo foi construído privilegiando a modernização da esfera pública e a participação cidadã em espaços que contemplassem as tomadas de decisão. Cabe mencionar, que desde a revolução tecnológica do século XX o uso das TIC e da internet se tornou uma realidade cada vez mais presente inclusive no 
âmbito governamental e no seu modus operandi, especialmente à luz do discurso da modernização destes espaços, na busca pela eficiência e da qualificação dos bens e serviços públicos prestados à população.

No relatório do Plano Conceitual de Diretrizes Estratégicas do Gabinete Digital, produzido pela Fundação Getúlio Vargas ao governo, no final de 2011, enfatizava-se a intensão do governo do RS em "posicionar o Estado como referência nacional e global de renovação e adensamento democrático visando a transformação social" (RELATÓRIO DO PLANO CONCEITUAL DE DIRETRIZES ESTRATÉGICAS DO GD, 2011, p. 4).

O GD foi lançado no dia 24 de maio de 2011, anterior mesmo à formalização do SISPARCI, num evento realizado no Palácio Piratini e foi instituído por meio do Decreto $n^{\circ}$ 48.056, de 24 de maio de 2011, que instituiu no âmbito do governo estadual o GD do Governador do Estado e a Comissão Permanente de Cultura e Governança Digital. O GD fazia parte da dimensão da participação digital do SISPARCI e possuía quatro principais ferramentas: Governador Pergunta, Governador Responde, Governo Escuta e De Olho nas Obras.

\section{Figura 2 - Tela inicial do portal do Gabinete Digital}

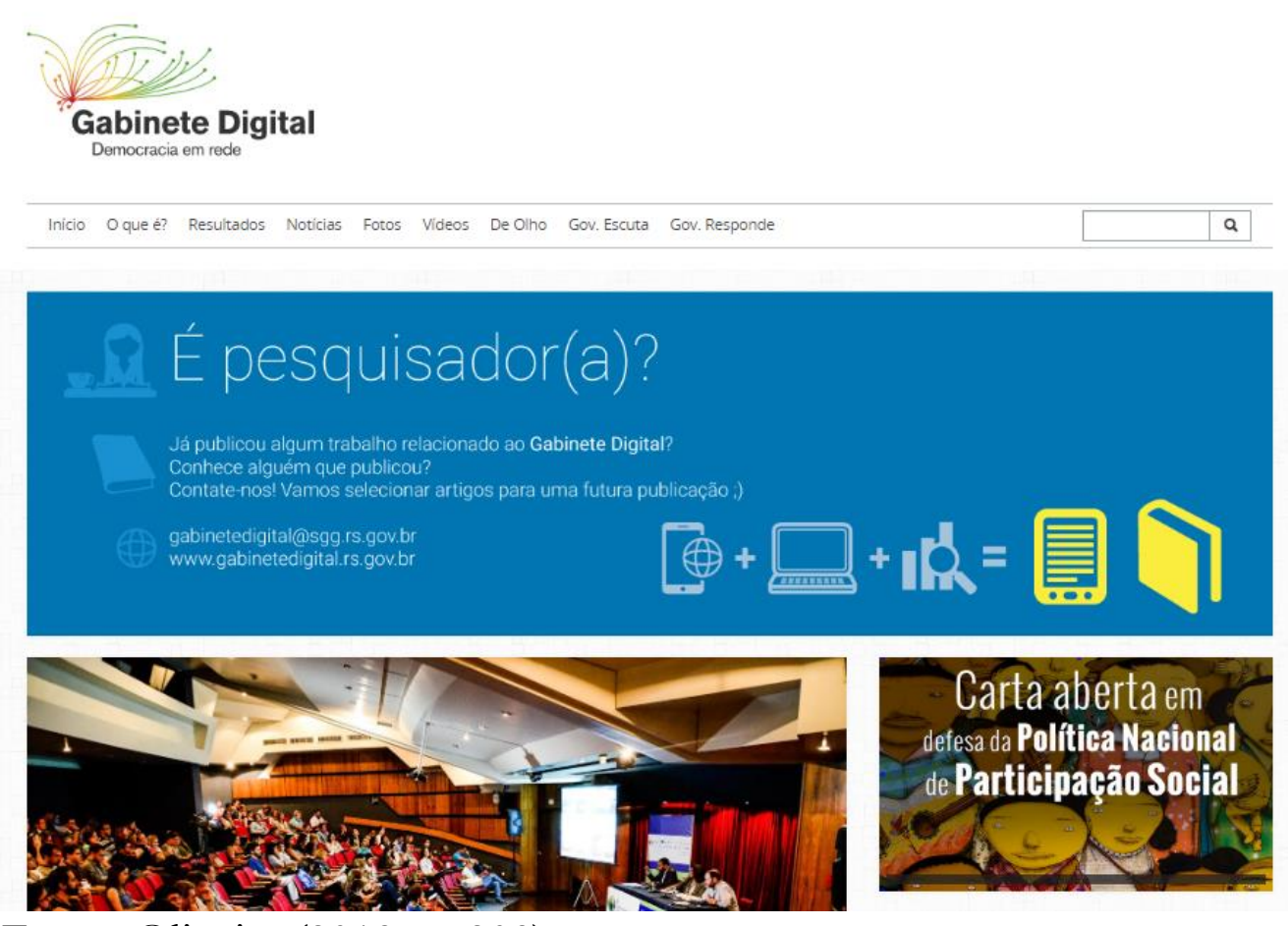

Fonte: Oliveira (2019, p. 203).

Para "alguns setores da esquerda, que davam sustentação ao governo, e dentro do próprio governo, ele [GD] não deixou de ser visto com uma certa desconfiança pelas pessoas, por acharem que participação por meio digital ela é mais fluida, 
menos consistente, [...]" (SECRETÁRIO DA SGG E COORDENADOR GERAL DO GD, 2018). Em sentido próximo, o Articulador de Políticas Digitais do GD reforça esse entendimento de desconfiança e negatividade com que o GD era visto dentro do governo.

o gabinete tinha uma dificuldade enorme no começo, até 2013, de explicar a sua existência, de não ser só uma coisa de sei lá, de moleque, enfim. Tinha uma leitura interna do governo, não de todo governo, claro, mas de parte ali mais conservadora do governo, bastante negativa, preconceituosa, assim do gabinete (ARTICULADOR DE POLÍTICAS DIGITAIS DO GD, 2018).

A partir dessa percepção de alguns membros do governo, tornar o GD um elo estratégico de integração de uma política mais ampla e consistente de democracia em rede ou digital se tornou um desafio ainda maior dado o curto período entre a implementação e a consolidação dessa experiência.

O aspecto cultural contrário à inovação na administração pública foi um fator de resistência ao desenvolvimento de meios mais efetivos para participação cidadã com uso de ferramentas digitais. A transição para um modelo democrático cada vez mais digital é contraditório e dialético, pois se, por um lado, o seu uso pelo governo não representa, necessariamente, um modismo, também não é a solução para todos os problemas relacionados a esfera democrática e da gestão pública.

A missão do GD era a de "colaborar com a construção de uma nova cultura de participação no Governo do Estado do Rio Grande do Sul por meio das redes digitais visando ao diálogo permanente com a sociedade, a transparência, a gestão colaborativa e a cidadania" (RELATÓRIO DO PLANO CONCEITUAL DE DIRETRIZES ESTRATÉGICAS DO GD, 2011, p. 34). Bem como de se consolidar enquanto uma "referência na utilização e compartilhamento de tecnologias digitais para a participação democrática em rede" (RELATÓRIO DO PLANO CONCEITUAL DE DIRETRIZES ESTRATÉGICAS DO GD, 2011, p. 34).

Como reforçam os sujeitos entrevistados nessa pesquisa, a aproximação da população com os processos participativos, o que leva ao entendimento e consolidação, dá-se por meio de um processo lento e gradual, em que as pessoas participantes percebem a materialização da sua participação no seu cotidiano.

Entre os resultados identificados da experiência do GD, destacam-se nesse artigo, a participação da população nas três consultas públicas virtuais realizadas pela ferramenta do Governador Pergunta. Na primeira edição, em 2011, com o tema da pergunta encaminhado pelo governo à população [Como podemos melhorar o atendimento à saúde pública?], foram enviadas 1.405 propostas pela população, tendo sido priorizadas 50, com um total de 122.609 votos. Já na segunda edição, em 2012, 
[Como governo e sociedade podem, juntos, promover a paz no trânsito?], foram enviadas 2.111 propostas, das quais 10 foram priorizadas, tendo havido 240.516 votos. $\mathrm{Na}$ terceira e última edição, em 2013, o tema foi a Reforma Política, que teve 2.840 propostas enviadas, tendo sido 10 priorizadas, com um total de 181.759 votos.

$\mathrm{Na}$ percepção dos entrevistados, a terceira edição do GP foi uma das mais importantes, dado a conjunta social e política de 2013, ano em houve intensas manifestações populares em todo o país. Neste sentido, uma das consultas se referia à reforma política, no qual 80\% dos participantes destacaram preferir que ela fosse realizada por meio de uma constituinte exclusiva e $20 \%$ acreditavam que ela devesse ocorrer pelo então atual (2013) conjunto de representantes eleitos no congresso. Quanto ao questionamento sobre quais deveriam ser as prioridades da reforma política, o fim do voto secreto no Congresso Nacional e demais instâncias legislativas foi a mais votada.

No Governador Responde (GR), desde o lançamento do GR, em 2011, foram realizadas 15 edições e enviadas mais de 500 perguntas e 105 respondidas (BALANÇO 2011-2014 DO GD, 2014, p. 16). Interessante destacar que houve uma apropriação desta ferramenta por setores associados ao governo, o que pode ser identificado a partir das questões enviadas para a ferramenta. Pode-se dizer que ela foi restrita, em grande medida, aos servidores públicos, sejam eles relacionados à segurança pública ou à educação. A exemplo disso foi a desvinculação dos Bombeiros da Brigada Militar que surge nas entrevistas como um dos grandes resultados desta ferramenta.

Até porque são categorias [servidores] já previamente organizadas, então eles têm muita facilidade de, por exemplo, no período de votação, conseguir fazer com que as suas perguntas ganhem de uma pergunta que é atomizada, de um cidadão que não está organizado ou que tem um interesse que não é exatamente o interesse de classe ou de categoria [...] (COORDENADOR EXECUTIVO DO GD, 2018).

Já nas 15 edições do Governo Escuta (GE) houve um total de 700 mil participações (BALANÇO 2011-2014 DO GD, 2014). Das 15 edições do GE, as audiências sobre o Passe Livre Estudantil, a Conscientização Contra o Bullying, o Veto à Lei de Estrangeirismos são lembradas pelos entrevistados como sendo as principais realizadas pela ferramenta.

Especialmente em relação ao Passe Livre Estudantil, na percepção dos entrevistados, o uso das TIC e da internet foram essenciais para que fosse possível estabelecer um canal de diálogo direto com os movimentos sociais e demais sujeitos que protagonizaram as manifestações de 2013. Como aponta o Coordenador da Divisão Digital do Deparci (2017), "nos movimentos de junho de 2013, foi quando, principalmente através do Gabinete Digital, se usou bastante as ferramentas de TI 
para diálogo social. [...] tudo usando tecnologias de informação", que resultou na Lei do Programa Passe Livre Estudantil.

O Diretor do Deparci (2018) compreende que o GD teve uma importância significativa durante as jornadas de junho de 2013 e no processo de diálogo com os manifestantes. Isto se deve, principalmente, pelo fato de o GD ter proporcionado novas formas de participação digital. Como havia uma familiarização dos manifestantes com o uso das TIC e da internet para as suas mobilizações, pois em grande medida os protestos foram organizados e convocados pelas redes sociais, então, “já era uma coisa bem espraiada entre eles” (DIRETOR DO DEPARCI, 2018).

Desta maneira, a partir da percepção dos integrantes do governo, tinha-se o entendimento de que a experiência do GD estava consolidada, muito em decorrência dos resultados que se vinha alcançando por meio dos diversos canais de participação e de interação da sociedade com o governo.

\section{O uso das TIC no governo Tarso na percepção dos atores}

Numa concepção de estado democrático de direito, sob regime político representativo, os governos eleitos por sufrágio universal têm autonomia para adotar diferentes estratégias governamentais, mas que nem sempre são tensionadas pelo viés participativo e/ou deliberativo. Portanto, sua adoção pelos governos depende, em grande medida, da disposição deles, seja no sentido de utilizar as TIC e a internet apenas para atender os marcos legais, especialmente os definidos nas Leis de Responsabilidade Fiscal (LRF) e de Acesso à Informação (LAI), ou mesmo no sentido de ampliar a participação cidadã nos espaços públicos e no fortalecimento da práxis democrática.

Como destaca o Secretário da SGG e Coordenador Geral do GD (2018), a participação e uso das tecnologias para além do marco legal depende de um componente político.

Não adianta, o governante tem que ter a disposição e querer, efetivamente, abraçar essa agenda da participação. Mas ainda que tenha também esse compromisso, só ele também não resolve, porque você tem que ter metodologias, você tem que ter capacidade de coordenação interna, você tem que ter uma série de requisitos, vencer as amarras institucionais, e às vezes até resistências, por exemplo, do Legislativo que muitas vezes percebe a participação da cidadania como um esvaziamento das suas funções (SECRETÁRIO DA SGG E COORDENADOR GERAL DO GD, 2018).

nós temos que ter uma outra visão sobre essa questão da democracia mais contemporânea, que incorpora as novas tecnologias e que dê uma 
dinâmica mais ativa para a participação do indivíduo. É como o professor Boaventura [Sousa Santos] chama de democracia de alta intensidade. É esse tipo de dinâmica que se quer no governo [...], progressista, aberto, e assim por diante (SECRETÁRIO DA SPGPC, 2018).

No campo democrático, por exemplo, de acordo com a Assessora de Planejamento da Procergs (2018), as tecnologias podem ser componentes estratégicos para aumentar a participação cidadã e promover uma integração entre governo e sociedade. Isto porque

as pessoas são digitais, os cidadãos são digitais, o mundo é digital. Então, o governo tem que ser digital. Então, assim, a tecnologia é estratégica, é muito estratégica. As pessoas estão em rede, a gente tem que encontrar esse cidadão, ele tem que nos encontrar [governo], tem que ser fácil de usar, tem que ser acessível (ASSESSORA DE PLANEJAMENTO DA PROCERGS, 2018).

Observa-se que o uso das tecnologias no âmbito governamental ocorre a partir de um certo entusiasmo perante as possibilidades e contribuições para a participação cidadã, para o aprofundamento e acesso democrático.

Para o governador do RS (2018), a implementação do SISPARCI e do GD, a partir das suas ferramentas, contribuiu para que houvesse no Estado uma qualificação e aprofundamento da práxis democrática. Contudo, ressalta que, ainda que se tenha havido um acúmulo, ele não

permaneceu com solidez. Porque é necessário, vamos dizer assim, que esses processos tenham continuidade até proporcionar, até 0 momento em que proporciona uma mudança na cultura política da sociedade, que passa a respeitar esses mecanismos e haja, também, uma modificaşão na cultura política, na cultura cidadã dos próprios servidores públicos. Eu tenho certeza que isso começou, com essas experiências democráticas aqui no Rio Grande do Sul. Com essas experiências, inclusive, que refletiram numa reorganização das nossas políticas públicas. (GOVERNADOR DO RS 2011-2014, 2018, grifos nossos).

Portanto, pode-se observar ao menos três entraves para a ampliação das potencialidades democráticas e da participação cidadã à luz do incremento das TIC e da internet na gestão de Tarso Genro. O primeiro é a ausência de mecanismos participativos efetivos e consolidados, os quais não estão suscetíveis à troca de governos, pois são instituídos enquanto uma política de Estado e não de governo; 
já o segundo é o engajamento das pessoas nestes processos; e o terceiro guarda relação com a instituição midiática não divulgando e não estimulando a participação.

No primeiro caso, identifica-se ao menos dois fatores: as amarras institucionais, que não só dificultam o desenvolvimento de iniciativas participativas como também são, muitas vezes, impeditivos da presença da sociedade na gestão pública e seu envolvimento em processos decisórios. Outro fator é o elemento político, do querer fazer, mas que também depende de uma articulação interna no governo com a sua base aliada e de oposição. Nesse sentido, o Governador do RS (2018) destacou, a partir do exemplo do Orçamento Participativo (OP) de Porto Alegre - de que fez parte enquanto prefeito -, que a consolidação da participação na sociedade se constrói a longo prazo. "A cultura participativa, tanto nas cidades, quanto no Estado, ela se dá de maneira cumulativa e com ascensos e descensos, dependendo dos governos, [...] e ela não condensa em determinado momento e permanece naquele nível". Por meio da história do OP, ele explica que, no caso dessa experiência, há uma consolidação da participação, pois está na memória das pessoas, criando uma resistência e uma vontade de participação permanente. E essa cultura participativa faz com que o governo em exercício, independentemente de seu posicionamento político, dê continuidade à experiência.

A consolidação do componente participação, que foi proposto a partir do SISPARCI, não se efetivou, ainda que se reconheça o pioneirismo e os avanços que se teve. São indicativos disso, a descontinuidade dos SISPARCI e do GD.

Já com relação ao segundo entrave, pode-se dizer que envolve um fator cultural: a sociedade não reconhece esses processos, e muitas vezes os gestores públicos também não acreditam, pois, os resultados e a efetividade da sua adoção não são perceptivos e materializados no curto prazo. Isto não gera um engajamento da população em participar e tampouco gera uma pressão popular para a manutenção e continuidade de experiências participativas. Além disso, identifica-se, ainda, a ausência de uma cultura participativa que ultrapasse a votação de prioridades da chamada Consulta Popular (CP).

No terceiro aspecto, a mídia comercial pode ser considerada um entrave. Embora não se tenha realizado na pesquisa a análise a cobertura da mídia tradicional comercial sobre o SISPARCI, a problemática da falta de adesão da mídia estadual e regional foi apontada pelo governador do Estado. O sistema foi divulgado majoritariamente por meio das mídias do governo e do Estado, que têm certo poder de alcance limitado, geralmente complementado por meio da mídia tradicional massivo no caso de campanhas ou informações sobre a gestão estadual.

Para o Governador do RS (2018), o espírito participativo na sociedade se forma, entre outros, a partir do trabalho de uma "vanguarda política mais organizada", o que incluiria, na sua opinião, partidos, grupos sociais, associações e academia, e não de uma vontade genuína em participar. A educação para a cidadania e o acesso à 
informação e ao conhecimento são, portanto, aspectos-chave na percepção de alguns sujeitos entrevistados para que haja a formação de uma cultura participativa. Contudo, faz-se importante mencionar que quando o SISPARCI e o GD foram implementados, para além das dificuldades de se romper com determinadas resistências em relação à adoção das TIC e da internet, havia dificuldades de infraestrutura de acesso a essas comodidades nos domicílios do RS, que à época era de apenas $33 \%$.

Observou-se, mesmo posteriormente à experiência, um otimismo com relação ao uso das tecnologias para democracia participativa e deliberativa por parte de alguns membros do governo, mas também uma visão negativa e resistente ao uso das TIC para a promoção da participação, bem como uma resistência aos próprios processos participativos identificados pelos entrevistados.

Evidencia-se a existência de uma necessidade não só de mudança da cultura política dos gestores públicos, mas também na sociedade sobre a participação e do fazer política. A descontinuidade das experiências desenvolvidas na gestão Tarso Genro e a não cobrança da população pela sua continuidade, são indicativos de uma carência de um processo educativo, de formação, para além da disponibilização de meios para a participação cidadã via TIC. A participação cidadã no Rio Grande do Sul não faz parte da cultura cidadã de forma homogênea, mas, sim, da consciência cidadã de alguns grupos que melhor se organizam, articulam, mobilizam e são politizados. Mesmo que os mecanismos de participação democrática estejam na memória da sociedade gaúcha, ou em parte dela, não se trata de elementos presentes em seu cotidiano. E ainda menos presentes são os resultados desses processos.

Portanto, não basta somente disponibilizar acesso às TIC em termos de infraestrutura, é preciso que haja uma preocupação em elaborar estratégias com vistas a uma educação para a cidadania e ao acesso a uma informação independente e de qualidade, para que haja, de fato, a formação e o fortalecimento dessa cultura participativa cidadã entre toda a sociedade gaúcha.

\section{Considerações finais}

Se por um lado o uso das tecnologias está relacionado a uma perspectiva entusiasta acerca do seu potencial democratizante, de outro, uma visão crítica sobre o seu uso. A visão crítica associa o uso das tecnologias a processos sociais e culturais, isto é, trata-se de uma compreensão que entende a técnica não como autônoma à sociedade, mas como resultado de seu uso, das suas intenções, dos seus propósitos e aspirações. É preciso, portanto, inserir a tecnologia dentro de uma dinâmica de interrelação com os demais fenômenos do mundo da vida, que formam a estrutura social. 
A gestão do governo Tarso foi fundamentada na égide da participação direta, voluntária e universal com caráter deliberativo dos cidadãos, em que, por meio do uso das ferramentas tecnológicas, ampliou-se não só a participação dos cidadãos na esfera pública por meio do desenvolvimento do SISPARCI e do GD, mas também promoveu uma cogestão com os cidadãos por meio do compartilhamento do poder decisório. Algo que até então só se tinha feito no Rio Grande do Sul por meio do OP em nível municipal e com a CP a nível regional.

O SISPARCI e o GD representaram uma importante inovação institucional para o fortalecimento da democracia participativa e deliberativa e que sua construção foi pioneira e lançou luzes de que é possível desenvolver uma gestão em que há um maior compartilhamento do poder decisório junto ao demos, para além das reconhecidas experiências participativas do OP e da CP.

No entanto, a partir da percepção dos atores, constatou-se que a resistência ocorreu, em grande medida, decorrente de uma preocupação de que, ao proporcionar à população canais para uma participação mais direta entre Estado e sociedade, haveria um esvaziamento das funções do executivo e legislativo.

Cabe lembrar, que a história da sociedade brasileira, e por consequência da democracia brasileira, é marcada por conflitos, contradições, desigualdades e por relações de dominação e de poder. A herança do patrimonialismo, do clientelismo e do coronelismo, ainda são elementos presentes na formação do Estado brasileiro, na dinâmica das relações políticas, das regiões e dos territórios. Além disso, o país viveu duas décadas de Ditadura Militar (1964-1985) e, com a redemocratização de 1988, tem-se um esforço de resgate do espírito participativo por parte de alguns grupos da sociedade civil organizada engajados nos processos políticodemocráticos, filiados à perspectiva de uma democracia participativa e deliberativa, que busca, por diversos meios, a soberania popular.

Se por um lado a continuidade das experiências participativas com vistas a aprofundar a democratização do Estado e o desenvolvimento regional por meio da participação cidadã depende de uma vontade dos gestores públicos, de outro é preciso considerar que não houve uma mobilização da sociedade civil pela sua continuidade. Fato este perceptível tanto pela não reeleição do governador ao executivo do RS, em 2014, quanto pela ausência de movimentos expressivos da sociedade para evitar a descontinuidade do SISPARCI e do GD na nova gestão do executivo gaúcho, em 2015. Entende-se que o desenvolvimento da experiência do GD e do SISPARCI representou uma tentativa do governo para ressignificar a estrutura de participação do Estado do RS e de avançar para além das experiências do OP e da CP, com vistas a adaptar os mecanismos participativos à sociedade em rede. 


\section{Fonte(s) de Financiamento}

CAPES-Coordenação de Aperfeiçoamento de Pessoal de Nível Superior.

\section{Referências}

ARTICULADOR DE POLÍTICAS DIGITAIS DO GD. O Sistema Estadual de Participação Popular e Cidadã e o Gabinete Digital. Entrevistador: V. G. Oliveira. 2018. Arquivo de áudio digital (1h08min). Entrevista concedida à pesquisa Democracia digital e participação cidadã: o Sistema Estadual de Participação Popular e Cidadã da gestão de Tarso Genro/RS no período de 2011 a 2014.

ASSESSORA DE PLANEJAMENTO DA PROCERGS. A Consulta Popular. Entrevistador: V. G. Oliveira. 2018. Arquivo de áudio digital (1h40min). Entrevista concedida à pesquisa Democracia digital e participação cidadã: o Sistema Estadual de Participação Popular e Cidadã da gestão de Tarso Genro/RS no período de 2011 a 2014.

BALANÇO 2011/2014 DO GD. 2014. Disponível em: https://issuu.com/uira/docs/balanco-gabinetedigital-2011a2014. Acesso em: 07 nov. 2016.

RELATÓRIO DO PLANO CONCEITUAL DE DIRETRIZES ESTRATÉGICAS DO GD. Porto Alegre, 2011.

CASTELLS, M. A Era da informação: economia, sociedade e cultura, vol. 1. 8 ed. São Paulo: Paz e Terra, 2005.

\section{COORDENADOR DA DIVISÃO DIGITAL DO DEPARCI. Consulta}

Popular. Entrevistador: V. G. Oliveira. 2018. Arquivo de áudio digital (1h56min). Entrevista concedida à pesquisa Democracia digital e participação cidadã: o Sistema Estadual de Participação Popular e Cidadã da gestão de Tarso Genro/RS no período de 2011 a 2014.

\section{COORDENADOR EXECUTIVO DO GD. O Sistema Estadual de} Participação Popular e Cidadã e o Gabinete Digital. Entrevistador: V. G. Oliveira. 2018. Arquivo de áudio digital (1h21 min). Entrevista concedida à 
pesquisa Democracia digital e participação cidadã: o Sistema Estadual de Participação Popular e Cidadã da gestão de Tarso Genro/RS no período de 2011 a 2014.

DECRETO No 49.765, DE 30 DE OUTUBRO DE 2012. Institui o Sistema Estadual de Participação Popular e Cidadã - SISPARCI. Disponível em: http://www.al.rs.gov .br/filerepository/replegis/arquivos/dec\%2049.765.pdf. Ac esso em: 25 out. 2016.

DECRETO No 48.056, DE 24 DE MAIO DE 2011. Institui o Gabinete Digital do governador do Estado e a Comissão Permanente de Cultura e Governança Digital, e dá outras providências. Disponível em: http://www.al.rs.gov.br/legis/M010/M0100099. Acesso em: 25 ou. 2016.

\section{DIRETOR DO DEPARCI. O Sistema Estadual de Participação Popular e} Cidadã e o Gabinete Digital. Entrevistador: V. G. Oliveira. 2018. Arquivo de áudio digital (1h03min). Entrevista concedida à pesquisa Democracia digital e participação cidadã: o Sistema Estadual de Participação Popular e Cidadã da gestão de Tarso Genro/RS no período de 2011 a 2014.

GOMES, W. A democracia digital e o problema da participação civil na decisão política. Revista Fronteiras, vol. 7, n. 3, p. 214-222, set./dez. 2005. Disponível em:

http://www.revistas.unisinos.br/index.php/fronteiras/article/view/6394/3537. Acesso em: 05 ago. 2016.

\section{GOVERNADOR DO RS. Democracia, Participação e o Sistema Estadual} de Participação Popular e Cidadã e o Gabinete Digital. Entrevistador: V. G. Oliveira. 2018. Arquivo de áudio digital (22min). Entrevista concedida à pesquisa Democracia digital e participação cidadã: o Sistema Estadual de Participação Popular e Cidadã da gestão de Tarso Genro/RS no período de 2011 a 2014.

OLIVEIRA, V. G. Democracia digital e participação cidadã: o Sistema Estadual de Participação Popular e Cidadã da Gestão do Governo Tarso Genro/RS (2011-2014). 2019. Tese (Doutorado em Desenvolvimento Regional) PPGDR/UNISC, Santa Cruz do Sul, 2019. Disponível em: https://repositorio.unisc.br/jspui/bitstream/11624/2480/1/Vinicios\%20Gonch oroski $\% 20$ de $\% 20$ Oliveira.pdf. Acesso em: 10 mai. 2020. 
ONU. Relatório da Organização das Nações Unidas sobre o governo eletrônico e participação eletrônica nos países integrantes da ONU. S.l.: Organização das Nações Unidas, 2016. Disponível em: http://workspace.unpan.org/sites/Internet/Documents/UNPAN96407.pdf. Acesso em: 20 mar. 2017.

PINTO, A. V. O conceito de tecnologia, vol 1. Rio de Janeiro: Contraponto, 2005.

PRESIDENTE DO COREDE SUL E INTEGRANTE DA COMISSÃO ESTADUAL DA CP. Consulta Popular. Entrevistador: V. G. Oliveira. 2018. Arquivo de áudio digital (1h06min). Entrevista concedida à pesquisa Democracia digital e participação cidadã: o Sistema Estadual de Participação Popular e Cidadã da gestão de Tarso Genro/RS no período de 2011 a 2014.

PROGRAMA DE GOVERNO TARSO. Rio Grande do Sul do Brasil e do Mundo. Porto Alegre, 2010. Disponível em: http://www1.SEPLAG.rs.gov.br/upload/Programa_de_Governo_Tarso_Genro. pdf. Acesso em: nov. 2016.

SECRETÁRIO DA SGG E COORDENADOR GERAL DO GD. O Sistema Estadual de Participação Popular e Cidadã e o Gabinete Digital.

Entrevistador: V. G. Oliveira. 2018. Arquivo de áudio digital (1h28min). Entrevista concedida à pesquisa Democracia digital e participação cidadã: o Sistema Estadual de Participação Popular e Cidadã da gestão de Tarso Genro/RS no período de 2011 a 2014.

SECRETÁRIO DA SPGPC. O Sistema Estadual de Participação Popular e Cidadã e o Gabinete Digital. Entrevistador: V. G. Oliveira. 2018. Arquivo de áudio digital (53min). Entrevista concedida à pesquisa Democracia digital e participação cidadã: o Sistema Estadual de Participação Popular e Cidadã da gestão de Tarso Genro/RS no período de 2011 a 2014.

SANTOS, M. A natureza do espaço: técnica e tempo, razão e emoção. 4 ed. São Paulo: Edusp, 2014. 
SANTOS, B. de Sousa. Introdução geral à coleção. In: SOUZA SANTOS, B. de (Org.) Democratizar a democracia: os caminhos da democracia participativa. Rio de Janeiro: Civilização Brasileira, 2002. p. 13-28. Disponível em: http://www.do.ufgd.edu.br/mariojunior/arquivos/boaventura/democratizardem ocracia.pdf. Acesso em: 25 set. 2018.

THOMPSON, J. B. A mídia e a modernidade. Petrópolis: Vozes, 2002.

Data de submissão: 26/05/2020

Data de aprovação: 14/07/2021

Revisão: Daniela Matthes (português), Anderson de Miranda Gomes (inglês) e Yanet María Reimondo Barrios (espanhol).

Vinicios Gonchoroski de Oliveira

Universidade Regional do Noroeste do Estado do Rio Grande do Sul

Rua do Comércio, 3000 - Bairro Universitário

98700-000 Ijuí/RS, Brasil

Orcid: http://orcid.org/0000-0003-1158-3398

E-mail: viniciosgdoliveira@gmail.com

Angela Cristina Trevisan Felippi

Programa de Pós-Graduação em Desenvolvimento Regional / Universidade de Santa

Cruz do Sul

Avenida Independência, 2293 - Bairro Universitário

96815-900 Santa Cruz do Sul/RS, Brasil

Orcid: http://orcid.org/0000-0003-3545-0215

E-mail: angelafe@unisc.br 
Vinicios Gonchoroski de Oliveira e Angela Cristina Trevisan Felippi

116 | Revista Brasileira de Desenvolvimento Regional, Blumenau, 9 (3), p.89-116, 2021 